\title{
MÁS ALLÁ DE LAS FRONTERAS DE LA CIUDAD: LA VIDA EN EL ESPACIO DE LA EXCLUSIÓN
}

\section{BEYOND THE CITY FRONTIERS: LIFE IN THE SPACE OF EXCLUSION}

\author{
Laura Chacón Echeverría* \\ Jimmy Zúñiga Rodríguez ${ }^{* *}$
}

\begin{abstract}
RESUMEN
Este artículo destaca la experiencia subjetiva del desplazamiento forzoso de los habitantes de la Finca San Juan ubicada en Pavas, encabezada por el Estado en 1992. Se realiza un análisis de las dificultades enfrentadas por los desplazados en la apropiación simbólica de un espacio asignado. Como resultado se identifican tres modalidades de resistencia ante el poder: las conductas antisociales como forma de inclusión, la aceptación a su destino como forma de no-resistencia y la construcción de su comunidad como una forma de reinvención.
\end{abstract}

PALABRAS CLAVE: ESPACIO URBANO * EXCLUSIÓN SOCIAL * RESISTENCIA * VIOLENCIA

\section{ABSTRACT}

This article highlights the subjective experience of forced relocation of the habitants of Finca San Juan, headed by the state in 1992. This paper examines how the impoverished people of Pavas managed the difficulties of the symbolic appropriation of the space to which they were assigned. As a result, three patterns of resistance were identified: antisocial behaviours as a form of inclusion, the acceptance of their fate as a form of non-resistance and the construction of their community as a form of care of the self.

KEYWORDS: URBAN SPACE * SOCIAL EXCLUSION * RESISTANCE * VIOLENCE

* Escuela de Psicología de la Universidad de Costa Rica (UCR). Instituto de Investigaciones Sociales (IIS) de la Universidad de Costa Rica (UCR). Programa de Redes para la Prevención del Menor en Riesgo Psicosocial del Hospital Nacional Psiquiátrico Manuel Antonio Chapuí, en Pavas, Costa Rica.

laurachaconecheverria@gmail.com

** Programa de Redes para la Prevención del Menor en Riesgo Psicosocial del Hospital Nacional Psiquiátrico Manuel Antonio Chapuí, en Pavas, Costa Rica.

jzjimmyzuniga@gmail.com 
Desde la semántica del espacio, el oeste de Pavas es una geografía de exclusión. Se encuentra al límite del espacio habitable de la ciudad, entre pronunciados acantilados cruzados por los ríos que atraviesan la ciudad donde coexiste con otros espacios de expulsión y de desecho. El Hospital Nacional Psiquiátrico, institución históricamente a cargo del depósito social de la enfermedad mental, da la entrada a este espacio.

Se exploró en seis relatos los triunfos y derrotas de habitantes, dos hombres y cuatro mujeres de estos barrios, quienes intentan ejercer su derecho a una habitación digna, frente a condiciones económicas de alta desigualdad y una política estatal que impone sobre ellos su violencia territorial. El objetivo fue destacar la experiencia subjetiva del desplazamiento de la Finca San Juan, en 1992.

\section{EL TRAZO, UN COMIENZO: SUEÑO Y PESADILLA}

En 1991, en el momento cero de la fundación sin decreto de este espacio, el proyecto de Finca San Juan fue planteado desde la instancia gubernamental como parte de un plan piloto para solucionar el problema del precarismo durante los quince años siguientes. Según lo relata Yonta, una de las entrevistadas:

- Existía en ese momento en el país, la Comisión Social de Vivienda [Comisión Especial de Vivienda] que había decidido sacar a todos los pobres del casco metropolitano y ubicarlos en un mismo sitio o en dos o tres sitios, pero que no fueran tantos (entrevista, 2012).

Asimismo, César, implicado en los movimientos de ocupación de terrenos en Pavas desde los años 80, relata cómo la Comisión Especial de Vivienda del Gobierno había comenzado la negociación:

- La negociación de dos, tres, cuatro, máximo cinco terrenos donde trasladar la gran cantidad de precarios pequeños que había en el "casco" metropolitano y en algunos otros sectores; trasladarlos $y$ empezar a construir allí habitaciones y viviendas (entrevista, 2012).
Desaparecer a los "precaristas" del casco central y juntarlos sobre la base de la exclusión, en terrenos fuera de visión, era una operación de limpieza de pobres; los medios de comunicación se unieron a esta creencia de la "desaparición de los precarios". En 1992, el periódico La Nación publica: "Precarismo pierde fuerza" (23/02/1992). Esta noticia relata traslados "voluntarios" de 850 familias de 8 distintos precarios de la Gran Área Metropolitana (GAM), a una finca recién comprada por el Estado, Finca San $J_{u a n}{ }^{1}$. El carácter voluntario del traslado era ilusorio, pocas líneas después se puede leer en palabras del Ministro de turno del Ministerio de Vivienda y Asentamientos Humanos (MIVAH), que "debían trasladarse antes de que se produzca la orden de desalojo".

Según la misma nota, los expertos comentaban que la Finca sería un "modelo" con lotes de cinco por diez metros, con agua, luz, letrinas $y$ a corto plazo, tendrían escuela $y$ centro de salud. La idea se vendió a los medios como una utopía urbana que debía beneficiar a los sectores más desfavorecidos; sin embargo, ninguna medida práctica fue considerada para su ejecución; el espacio receptor era una finca que no estaba dotada de ningún servicio. La violencia del "desalojo forzado" fue enmascarada con la figura de "traslado voluntario" y la fórmula "solución de vivienda" sirvió de pantalla al plan real de "trasladar los tugurios" a un espacio abyecto, excluido de la organización social de la ciudad; un espacio geográficamente aislado, recluido entre dos ríos en el límite de la cité.

José Gabriel Román, uno de los líderes asignados por el Gobierno algunos años antes para la ocupación de Finca San Pedro, mira con ojos críticos la organización de esta hora cero:

- La toma de la finca [San Juan] se hace completamente irracional... Primero que todo se llevan a las familias... no les dan solución... Los meten aquí bajo la idea de que iban a ser movilizados a otros lados... ese fue el problema fundamental... Ahí ibas a meter un

\footnotetext{
$1 \quad$ Para el año 1990, este espacio se encontraba pobla-
} do por los primeros ocupadores en precario. 
grupo de familias y que las familias se iban a quedar quietas ante el resto de la finca que se suponía que iba a ser un parque urbano (entrevista, 2012).

El corte de manera forzada con su hábitat, vecinos, hábitos espaciales y cercanía de su lugar de trabajo, implicaba un desrraizamiento de las comunidades. Lo sobrante de la pobreza, lo incapaz de insertarse al sistema de producción, era depositado como "desecho" en este mismo espacio. Su depósito transformaba esta finca en un espacio abyecto en el límite de lo visible:

- Fue el INvu el que dijo cuántas personas tenían que moverse de cada uno de los precarios, para ese momento decía este precario se mueve o de este precario se van a mover tantas familias y había que hacer la selección de esas familias, de ese número que se había dado, con unas boletas de ubicación diciéndole a las familias (Yonta, entrevista, 2012).

Las palabras de una desplazada señalan el deseo de los habitantes de los precarios de ser movilizados a la finca modelo, aunque solo algunos fueron elegidos:

- Ud. está siendo trasladado a un precario, el precario tal, Finca San Juan y tiene derecho a un lote en este lugar. Así nos dijeron a todas las familias, el INvU prestaba las vagonetas y ahí cada uno de las familias seleccionadas (Yonta, entrevista, 2012).

Los elegidos se sentían con clara ventaja en su solución habitacional y los vecinos del mismo precario "no elegidos", se lamentaban de no haber tenido la misma oportunidad. Sin embargo, la "tierra prometida" no era más que eso, no se trató del traslado de un hábitat, sino del corte casi azaroso entre vecinos de ocho precarios, siendo los "privilegiados" los que vivían la migración forzada y los "no elegidos" los que debían quedarse en el viejo precario. La violencia del traslado no pueden olvidarlo ni los niños, ni los adultos que vivieron la experiencia:
Echaron la poca comida que teníamos, alguna que otra olla con alguno que otro catre, todo revuelto en camioncillo que prestó el INvU y luego todo sucio y untado con comida nos lo vaciaron en la plaza para que buscáramos entre todos alguna pertenencia que nos había quedado de ese traslado (Yonta, entrevista, 2012)

"El olvido siempre está al lado del poder". Esta frase de Octavio Paz impulsa a rescatar los trazos de memoria que pueden servir para plantear una mayor justicia en la distribución desigual e inhumana del espacio. La memoria colectiva de la constitución del espacio puede ser un instrumento de resistencia ante las relaciones de dominación en las construcciones del espacio público y del espacio habitacional. En la línea del trabajo de Veschambre $(2008)^{2}$ se encuentra la pregunta por la memoria: ¿qué es lo que da identidad a cada colectivo? En el caso de la Finca San Juan, se trasladó a un grupo de personas de diferentes lugares, erradicando su memoria de lugar, para darles el mandato de apropiación, sin memoria común y sin identidad. La dificultad de adueñarse del espacio es evidente, pues asignación y expulsión son dos actos antagónicos de toda operación de apropiación. Fue un desplazamiento donde se depositaron, bajo el máximo desamparo, centenares de familias en un terreno desconocido: Finca San Juan. Este era el acto de rompimiento del sueño y el inicio de la pesadilla para enfrentar el día a día. Batalla cotidiana para defender el espacio asignado y no apropiado.

En el momento cero no solo se les trata como expulsados del espacio, llevándolos a una tierra de segregación, sino que se les trata como expulsados de la palabra, en la negativa estatal de darle al sujeto los medios para decidir sobre su propia historia, sobre su propio espacio. La causalidad parece ser la siguiente: dada su condición de expulsado de la esfera económica, ninguna solución habitacional les es permitida,

2 Su objeto se sitúo en el análisis de la apropiación simbólica del espacio, efectuando investigaciones en los campos de internamiento de los gitanos y la destrucción de la fábrica Renault, ambos en Francia. 
quedando a merced del Gobierno, el cual prescinde de su capacidad de decisión.

\section{LA MIGRACIÓN FORZADA: DESRAIZAR, DESALAMBRAR, ARRANCAR}

\section{Echábamos las latas o lo que tuvieran para trasladar el rancho a Finca San Juan...} Yonta, 2012

A esta migración se le ha llamado desplazamiento forzado. Se trata en primera instancia de un desplazamiento forzado con miras a excluirlos del espacio de la ciudad hacia otro lugar de destino - el de la exclusión-. La raíz etimológica de exclusión viene del latín clauder, significando cerrar y ex apartar, manteniendo cerrado un espacio como las grandes cárceles y los grandes manicomios. El sociólogo Loic Wacquant (2006) entiende el fenómeno de exclusión de la pobreza como la relegación forzada de una población estigmatizada.

El trazo de la humillación los une: siendo tratados como objeto a depositar y no como sujetos pensantes que deciden y crean. Cada quien deviene el espejo del otro, viéndose en el otro y rechazando este reflejo. Una vez depositados pasivamente en este espacio, los vecinos de Finca San Juan se organizaron para enfrentar las consecuencias de las acciones del poder. El derecho a una vivienda digna, en cuyo marco jurídico discursivo se estableció este traslado, estuvo más cercano al verbo depositar que al de construir. La modalidad del transporte en la migración forzada, objetos y sujetos recogidos, mezclados y echados, sin diferenciación alguna, mostraba la negligencia de la condición humana de los nuevos habitantes del lugar.

Siguiendo la enseñanza de De Certeau $(1984)^{3}$, el sujeto intenta a través de su táctica ${ }^{4}$

$3 \quad$ Ver también el artículo sobre Michel de Certeau en Crang, Mike y Thrift, Nigel (eds.). Thinking Space. Nueva York, Estados Unidos: Routledge, 2000.

"De Certeau (1984) junto con Michel Foucault, postulan que el poder tiene una dimensión espacial dado que la existencia social también la tiene, $y$ que el concepto de espacio nos permite interceder de modo complejo, a dimensiones intersubjetivas, socioculturales y sociopolíticas de la praxis de la dominación; de Certeau, en el lugar del poder, escapar de los desechos. La posibilidad de escape de los desechos no se logra a pesar de los esfuerzos. Bajo este vaticinio, se inicia la construcción de la comunidad. La táctica con la que este grupo se enfrentó a la estrategia espacial del Estado y a la organización que se les imponía, fue inicialmente un encuentro de solidaridad $y$ un intento de hacer una nueva vida:

Es una emoción ver que todo el mundo levanta sus ranchos, gente de primero, pero como que ahí no, yo vi como así, como envidias ni nada, la primera que levantaba su rancho primero metía a todos los chiquitos de todos los demás para que estuvieran ahí y no se fueran a mojar ni nada y ya se iban a ayudar a otros a construir (Yonai, entrevista, 2012).

\section{LOS OTROS, EL ESPEJO DEL DESECHO}

\section{El extranjero representa una sintesis disonante y ofensiva de proximidad y lejanía. Zygmunt Bauman, 1991}

A pesar de lo anterior, la creación del lazo social planteaó grandes dificultades porque los unía únicamente el trazo de la exclusión y como tal, se encontraban uno al lado del otro,

propone el término "estrategia" para realizar su análisis del espacio, y en el lugar de resistencia defiende la noción de "táctica". La táctica del sujeto es su resistencia a la dominación espacial. Las tácticas son los caminos donde los lugares se transforman en espacios, la forma que media y permite que el débil se transforme en fuerte. La táctica no tiene espacio propio, sino que procede desde el espacio del dominante. No son simplemente fuerzas reactivas o una práctica de respuestas, estas en sí misma son los límites de la estrategia y fuerzan a la estrategia a responderle. La táctica del sujeto es su resistencia a la dominación espacial, la forma que media y permite que el débil se transforme en fuerte. La estrategia es la que dicta la arquitectura deseada en una sociedad, la táctica es lo que revienta este discurso espacial $y$ hace emerger lo que el poder no legitima. La estrategia es la facultad del poder para hacer del espacio un lugar con la habilidad de determinar y dar forma a la conducta de los ocupantes autodeterminando la naturaleza y el tipo de habitante" (Chacón, 2013: 68). 
sin querer reconocerse. Todos los entrevistados tenían experiencias múltiples de desalojo y de expulsión gubernamental de otros precarios. Cada una de estas familias, había sido arrancada "voluntariamente" de su sitio de vida $y$ además, pasaba a recibir el trazo estigmatizante $y$ vergonzoso de ser de la Finca San Juan, donde el pasivo en sus acciones predominaba sobre sus propias decisiones. Al unir vecindarios sin otra homogeneidad que no fuera más que el mismo rasgo: ser un nómada de la miseria y no tener donde habitar, "los otros" — todos- habitantes recién llegados, construían el "nosotros" de la experiencia de haber sido depositado: "- La gente sentía que estaba en una situación de asfixia, entonces la gente empezó a invadir y meterse a la finca" (Santiago, entrevista, 2012). Cada uno se veía reflejado en el otro - todosdepósito de la miseria - todos- pasivos de situaciones de violencia extrema dada la condición de carecer de vivienda. Este reconocimiento en el otro pasaba por el trazo de la abyección. En esta vía de alteridad desde lo abyecto, los problemas entre los unos y los otros no tardaron en aparecer: "-Y hasta el mismo ranchito que yo había hecho ahí lo bajaron los precarios, entonces no, ya yo no me quise volver a meter en nada" (César, entrevista, 2012).

En la hora cero, el trazo identitario se componía de tres elementos: el desecho humano, la ausencia de identidad comunitaria de nadie con nadie y la violencia contra los mismos o contra otros diferentes.

Al lado de la Finca San Juan se encontraba una urbanización, relativamente reciente y llamada Santa Fe. Este "depósito de pobres" fue vivido violentamente por los vecinos de esta comunidad, cuya condición económica era superior. Estos sentían que su patrimonio, el valor de la propiedad, se había devaluado con la llegada de los "pobres": la violencia del trato entre nuevos y viejos vecinos comenzó. Las respuestas de violencia no tardaron en gestarse; al trato violento de los vecinos de Santa Fe que los insultaban de sucios, se respondió con un acto de suciedad. La narración de Ema lo expresa así: "-_La gente en el baño cagaba en una bolsa plástica y se la tiraba en el techo a los vecinos. O si no la echaban entre la basura" (Ema, entrevista, 2012).
Los "extranjeros", los recién llegados empezaron a tirar sus excrementos, mientras que los vecinos "autóctonos", seguían reproduciendo la violencia simbólica de tratarlos como excremento a expulsar. Modalidad equivocada de resistencia ante la violencia sentida. Los desechos personales no al basurero, ni a las cloacas, sino a los techos de los vecinos "detestados".

Para los vecinos con mayor capacidad adquisitiva, lo más temido y odiado pasó a ser "ellos". Ese extranjero caótico, "un pobre sucio" que había llegado para arruinar sus vidas. Como el pharmakon (Derrida, 1967), el extranjero "es polisemia, remedio y enfermedad". Remedio: los de Santa Fe, a pesar de su situación económica de clase media baja, podían ubicarse dentro de los "incluidos". Los expulsados de la tierra y del sistema de producción eran otros, los "nuevos" pobres que venían a iniciar el caos en sus vidas $y$ en su vecindario. Enfermedad: los nuevos contaminaban, devaluaban las propiedades $y$ aumentaban los niveles de peligrosidad de la zona. Extranjero disonante, desigual, alteridad radical, diferencia abyecta respecto a quienes vivían en Santa Fe.

Ante el caos simbólico se inaugura un nuevo mito: Santa Fe era una comunidad pura $y$ luego se contaminó de pobres sin casa $y$ de costumbres repudiables.

El extranjero tal y como lo formula Bauman (1991), quiebra todas las dicotomías que protegen del caos y este estaba expresándose en el lanzamiento de lo abyecto, del horror de la indeterminación. El excremento, lo más íntimo en el imaginario de cada sujeto, no debe de indeterminarse con el otro. Evidencia de un espacio caotizado que requería distinción.

El lenguaje permite diferenciar este caos de la indiscriminación: ellos-nosotros, los de aquí-los de allá. En palabras de Bauman: "el principal síntoma del desorden es el agudo malestar que sentimos cuando somos incapaces de interpretar correctamente y elegir entre acciones alternativas... La función del lenguaje es prevenir la ambivalencia" (1991: 74-75).

El lenguaje denotativo, en este caso particular, pretendía prevenir el malestar de la indeterminación, organizando el mundo entre propios $y$ ajenos, aquellos con derechos $y$ aquellos 
vueltos criminales y usurpadores. Para Bauman: "clasificar consiste en actos de inclusión y de exclusión. Cada acto de designación divide el mundo en dos... semejante operación de inclusión/exclusión es un acto de violencia perpetrado al mundo y requiere el soporte de una cierta coerción" (1991: 75).

La comunidad pasa a organizarse a través de un conjunto de oposiciones binarias: pobres-ricos, sucios-limpios, vagabundos-trabajadores, amigos-enemigos. Hermenéutica del afuera $y$ el adentro. Con el lenguaje, el uso de todas las modalidades corporales para expulsar al otro de su cercanía física o social. Siguiendo la lectura de Bauman, se describe la hermenéutica del extranjero:

El extranjero es un miembro de la familia de los innombrables - esas desconcertantes $y$ sin embargo, omnipresentes unidades que, en palabras de Derrida, "no pueden ser incluidos dentro de la oposición filosófica, a la que niegan y desorganizan, sin constituir un tercer término, sin dar salida a una solución bajo la forma de dialécticas especulativas"... innombrables son todos los ni esto/ ni aquello... Las oposiciones proporcionan conocimiento y acción, los innombrables las paralizan. Los innombrables exponen brutalmente el artificio, la fragilidad, lo postizo de las separaciones más vitales. Llevan sobre sí el exterior en el interior y corrompen el sosiego del orden con la sospecha del caos (1991: 95-96).

\section{LA FRONTERA SON LAS PIEDRAS}

La violencia se repite y profundiza como modo de resolución del caos. Esta no se establece únicamente entre los de Santa Fe y ellos, los recién llegados; sino que se amplía a otro grupo: los "olvidados", los no elegidos de los precarios del casco metropolitano, que llegaban para habitar la "tierra de la utopía". Los que quedaron en otros precarios sin ser seleccionados decidieron venir a ocupar Finca San Juan. $\mathrm{Al}$ anunciarse con fuerza que sería una finca modelo, los no elegidos del casco central empezaron a llegar exigiendo el derecho de vivienda digna que supuestamente se le había atribuido a sus anteriores vecinos:

- Cada día había más gente y más gente... empezamos a organizarnos más para no dejar meter a otro grupo, no había campo ya... ¡Cómo puede ser posible que la gente se dé cuenta lo que a mí me costó hacer eso y que al final del camino se metiera gente, $y$ cada uno que le echaban ahí le cobraban una cochinada, por meterlo ahí! (César, entrevista, 2012).

El Gobierno intervino para decir a los vecinos que no debían permitir la entrada de más personas, que la tierra era de los primeros y debían defenderla. Los habitantes se organizan y establecen una frontera. La consigna fue no dejar pasar a nadie más y "reventarle" piedras para que se fueran.

La violencia así establecida, se defendían con bolsas de excrementos de los vecinos de clase económica superior y de los otros, sus semejantes, se defendían con piedras para expulsarlos de su territorio.

Los "olvidados" llegaban en buses unos detrás de los otros. Quienes lograron traspasar la muralla de piedras, los nuevos llegados, se convirtieron a su turno en los extranjeros invasores. Los nuevos habitantes defendían su espacio y salían a recibirlos a pedradas para que se fueran; la vigilancia era las 24 horas. Lo que mucho les había costado no iban a perderlo. Los semejantes, habitantes en precario, en tanto nómadas de la miseria se transformaron en los extranjeros que debían ser expulsados, "nosotros, los de aquí, con derecho a habitar la tierra", "los otros, invasores sin derecho".

Como forma de defensa del caos se ensayaba establecer algún tipo de límite, aún si fuera por medio de la violencia. En palabras de Debray, quien trabaja el valor simbólico de la frontera:

¿Cómo fundar algo? ¿Cómo poner orden en el caos o configurar un sitio a partir de un sitio vago? Trazando una línea. 
Separando adentro y afuera. Autorizado y prohibido. La brujería de la frontera no tiene edad porque no existen treinta $y$ seis maneras de volver nada en algo... Dios separa las tinieblas de la luz... para extraer el cosmos de la sopa primitiva, el buen Dios, de un corte de bisturí, disjunta lo que era un conjunto-un verdadero diablillo (el divisor en griego). Sin ese impacto diabólico, no hay acceso al simbólico (2005: 25-26, traducción propia).

Se trataba de regularizar por una vía simbólica, los límites del espacio y de la incipiente comunidad:

- Nos habían advertido que ya la gente venía a invadir Finca San Juan, ya una vez que estaba tractoreada y limpia, venía gente de otros precarios. La gente que se quedó en los precarios, para venir a tomar la Finca. Entonces dormíamos parte de la noche, nos quedábamos las mujeres con fogatas prendidas en varias zonas de la finca, unas 10 familias cuidando y los hombres se levantaban temprano y relevaban a las mujeres, nosotras pasábamos toda la madrugada... Venía de todo. Gente muy osada que traía niños incluso, que eran un poco el escudo que utilizaban. Se usaban los niños de escudo, para que no fueran golpeados ponían los niños al frente (Yonta, entrevista, 2012).

Todos pasaron a convertirse en un ojo omnividente, ubicado tras su frontera de las piedras que debía vigilar a los otros que llegaban, para expulsarlos lo más pronto posible. Era la llegada de la sociedad de control a San Juan, como modo de acción del poder. Vigilar y no dormir era la táctica para defender su espacio y ante el arribo de los buses, la respuesta era lanzar piedras para que el nuevo enemigo tomara como fuerte el bus donde venía y sin bajarse, se fuera nuevamente. Fueron las autoridades gubernamentales quienes colocaron a los sujetos en el lugar de defensores de su "nuevo patrimonio", de su "nuevo espacio"; luego estas mismas autoridades gubernamentales no tuvieron la capacidad de prever ni de solucionar la llegada en masa de los excluidos del "idílico" plan del MIVAH. Ante la llegada de nuevos ocupadores la policía no pudo hacerse esperar más:

- Llegó la policía y los antimotines, la policía invadiendo, sacando gente y todo el mundo tirando piedras. La policía empezó a tirar gases y no sé quién trajo pistola y comenzaron a disparar, empezaron a disparar balas de verdad... Mataron a uno porque agarró la policía a balazos (Ema, entrevista, 2012).

La Finca San Juan, después de alguna meses, se encontraba fuera de control y la violencia era su marca permanente. La policía se defendía con sus armas y sus gases, los ocupadores resistían bajo el riesgo de ser asesinados por la policía y la guerra contra los desposeídos era la constante, dando como resultado la imposibilidad de expulsarlos a todos. Un año después, en lugar de 863 familias como previsto, se sumaban 1040 familias en Finca San Juan, y dos años después, 1300 familias. La violencia se constituyó como modo de vida y de defensa.

\section{EL CAOS NO SE FUE}

\section{El otro del orden no es otro orden: tan solo el caos es la alternativa. Zygmunt Bauman, 1991}

El caso de Finca San Juan muestra las estrategias espaciales del poder, en nombre de un bien supremo: la "desaparición" (¿ocultamiento?) de los precarios. Las acciones tomadas por el Gobierno, por candidez, ignorancia u otro adjetivo, condujeron a un estado de caos generalizado que las familias movilizadas tuvieron que experimentar desde el día cero. El orden de su cotidianeidad había sido destruido.

Los precarios se habían multiplicado y la mayoría de los habitantes vivían con múltiples necesidades básicas insatisfechas, comenzando por el estado de sus viviendas. En 1992, después del "depósito" inicial, solamente 55 familias habían sido instaladas en sus respectivos lotes y tenían sus casas en proceso de construcción, mientras que las restantes continuaban viviendo 
en los ranchos que construyeron a la hora del traslado de los precarios. En 1994 se publicó en el periódico La Nación: "En San Juan manda el caos" (02/10/1994). Este titular expresaba la situación de más de 1000 familias en un lugar inundado de problemas de higiene, en el que las aguas negras corrían por los patios de las casas y ninguna persona tenía título de propiedad. Tampoco el IMAS (dueño del terreno) había resuelto la situación; como forma de presión para la resolución de ese conflicto, los vecinos comenzaron a manifestarse.

La Finca San Juan se volvió un escenario de actos de violencia y dominación estatal; ante las manifestaciones de los vecinos, la policía respondía con gases. Luego del pésimo trato en el traslado, se usó la violencia para borrar la palabra y la posibilidad de decisión. La intervención de la represión estatal disolvía los vínculos comunales en la lucha política, obstaculizando el sentimiento de "sentir estar aquí, sentir ser de aquí" (Cordonianu-Thibault, 2011) . Se $^{5}$ dio un aumento de las grandes dificultades de apropiación simbólica del espacio y con esto, continuaban las manifestaciones en la calle por mejoras en su hábitat. La táctica de los nuevos pobladores, en la desprotección y el olvido, mostraba su semántica en esta comunidad: las tenis guindando de los cables eléctricos, el surgimiento de pequeñas organizaciones $y$ las luchas de vecinos ante el poder.

La apropiación simbólica y existencial del espacio no se había dado. La tierra no era sentida como propia, en consecuencia no era susceptible de ser cuidada, volviéndose únicamente un bien a partir del cual procurarse el mayor provecho mercantil inmediato. La supervivencia se impuso a los ideales ecológicos y estéticos del plan urbanístico, asimismo la tierra no fue apropiada como un espacio habitable donde construir su vida cotidiana. Según Román, dirigente de ocupación de Finca San Pedro:

$5 \quad$ Bouillon al estudiar las habitaciones precarias en Marsella, Francia, denominadas squats, plantea que justo el habitar en una inseguridad domiciliaria, es lo que impide el desarrollo del sentimiento "estar aquí, ser de aquí" (Bouillon, citado en Cordonianu-Thibault, 2011).
El Estado les cede ese terreno... entonces cada uno empezó a negociar con los lotes y se formó lo que se llama el carrusel... eso es que yo le doy el lote a una persona, la presiono para que se vaya y se lo vendo a otra... La arborización esa fue negocio, fue madera, incluso sacaban las matas de café y vendían las raíces. Aquí se sembró un germen de precarización y se sumó y se sumó (entrevista, 2012).

\section{LA ABYECCIÓN COMO RESISTENCIA}

El Estado no resuelve la situación de caos que inicia y las herramientas simbólicas no son suficientes para eliminar la indeterminación. La violencia en el lazo social se expresaba cotidianamente como modo de apropiación y de delimitación. La defensa del espacio se hacía a machetazos.

\section{- Entonces me dijo bueno, ahí hay un lote que no podrá ser tuyo, ese lote es de la vecina de al lado, que ella está ahí para que no nos invadan, pero es que ese lote no es de ella. Yo me fui para ahí y la señora se alcoholizaba, entonces me qui- taba la luz y me daba machetazos y me daba golpes, porque ella sentía que yo le iba a quitar el lote... Hasta la fecha recla- man 2 o 3 centímetros, a veces reclaman $20 y$ algunos atrevidos hasta de un metro (Yonta, entrevista, 2012).}

El espacio se había vuelto algo tan indeterminado que incluso unos pocos centímetros se volvían tan significativos como para ser causal de muerte. Los medios de comunicación dejaron de llamarla "finca modelo" e iniciaron una campaña de denuncia en torno al caos que reinaba.

En un espacio sin organización simbólica clara, excluido de los regímenes institucionales convencionales, las personas daban respuesta al caos desde la misma exclusión. El robo, el asalto $y$ la venta de droga pasaron a ser situados $y$ concentrados en este territorio como referente identitario, dándose una "mutación de sentido" (De Certeau, 1984) hacia un modo de resistencia al poder desde la transgresión. La resistencia 
pasó a expresarse en la "legítima" defensa de lo ilegítimo. La introducción de lo abyecto como modo de construcción identitaria se volvió una estrategia en la cual, la economía de la droga, el crimen y la violencia se planteaba como recurso abyecto que fungía como rasgo de inclusión.

Habitar en Finca San Juan, espacio de expulsión social y económica, imprime en quienes lo habitan el estigma (Goffman, 1968) de estar fuera de la ley, tanto en sus aspectos jurídicos (delincuente), como morales (vagabundo). Dicho estigma nutre una información al ojo externo y este a su vez, pasa a convertirse en un trazo. El sujeto llega entonces a reconocerse a sí mismo dentro del estigma asignado. Todas estas categorías de lo abyecto se constituyen en el trazo disponible para identificarse y producir un lazo social con los otros y con los miembros de la comunidad ¿El espejo de los otros que se ofrece a los poseedores en precario, es una "imagen de poseedor en precario" o una "imagen de poseedor en precario criminalizado"? Se juega aquí fuertemente una identificación con la exclusión.

- Aquí usted llama a la patrulla, apenas le dicen de Lajas para dentro dicen ahí no voy a entrar... porque si entra la policía por aquí ellos salen por cualquier lado... incluso, la Cruz Roja ya le ha pasado eso, le quitan los equipos y todo... Tal vez la falta de unión de la misma comunidad... los que empezaron a vender la droga son los hijos de los que se metieron aquí, usted sabe que los padres no van a denunciar a sus hijos por más malos que sean... Porque esta comunidad nunca ha dicho "hay que trabajar" (Santiago, entrevista, 2012).

Ante esta situación ¿cómo salirse del pasivo para encontrar el activo? La comunidad se vuelve el reflejo de la abyección, el desprecio está situado en el espacio de su hábitat, los otros habitantes de su espacio son los sucios, los criminales y los vagabundos. El lazo social se fractura al luchar más por la desidentificación y el desprecio al otro que por la unión en la consecución de metas compartidas. Habitar en Finca San Juan trata de una representación socio-espacial donde el estigma no se porta en el cuerpo, sino que es visible en referencia a ese espacio de alteridad en la geografía urbana, en la simple nominación de ser de Finca San Juan.

\section{INQUIETUD DE SÍ}

Cambiamos las piedras por los papeles... Yonta, 2012

Caminando por las calles de San Juan, los jóvenes indican - como si se tratara de comercios de una avenida-, esta o aquella casa comercial con una especialidad de droga. Actualmente, el narcotráfico ha inundado este sector que lucha por diferentes alternativas de subsistencia, grandes poblaciones en expulsión escolar y situaciones de delincuencia social. La venta de droga se ha vuelto una modalidad de subsistencia en familias afectadas por la extrema pobreza: "la comunidad está impregnada de drogas porque nosotros lo permitimos, la gente vende por comida y así" (Ema, entrevista, 2012).

Sin embargo esto no resume todo el acontecer en Finca San Juan. Sería injusto e insuficiente cerrar este artículo únicamente con la denuncia institucional o el pesimismo en la construcción del lazo social en dicha comunidad.

Algunas anotaciones al término "inquietud de sî" 6 aplicado a la casuística introducen a otro panorama igualmente presente en Finca San Juan. Si bien, la violencia está presente en la cotidianidad, en la lucha por los espacios, en los asaltos y en los rituales de incorporación de los nuevos miembros a las bandas, también existen iniciativas ciudadanas que impulsan otros modos de resistencia y por ende, de constitución de sí, en este espacio estigmatizado. En esta alternativa se intenta recuperar la condición humana frente a lo traumático del trato como desecho y de la humillación ¿¿cómo?,

$6 \quad$ La inquietud de sí tomó en la literatura helenística y romana la forma de una techné, un arte meditado, la preparación del sujeto y su alma de modo que estén armados para las circunstancias de la vida. La paraskeue tendía a lo que ellos llamaban la physiología, a form (Foucault, 2005). 
¿desde la violencia, desde lo abyecto o desde la inclusión simbólica?

La violencia puede ser un acto de resistencia contra la injusticia; sin embargo, el modo de resistir se manifiesta con matices diferenciales. En algunos, las acciones se dirigen hacia la edificación de una comunidad con menor violencia y con mayor posibilidad de vivir los unos al lado de los otros. Las narraciones de Ema, Yonta y Yonai muestran el arte de esculpir una vida en situaciones de gran desventaja social, cambiando la violencia de las piedras por la reinvención del espacio y de sí mismo. Yonta (entrevista, 2012) plantea esta disyuntiva: - "Compré un revolver, ya estaba decidida a mucho, $y$ en eso entendí que esta no era la vía".

¿Cómo un ser humano adquiere la preocupación sobre su propio destino, una inquietud de sí, la pregunta sobre su ser inscrito en su historia y su devenir? En medio de la bifurcación que presenta Yonta, ella ya estaba decidida a "mucho" por medio del revólver, pero ella entendió que matar no era la vía y algo cambió. La ética de una existencia puede abordarse desde la base de las elecciones tomadas en el transcurso de una vida: Yonta, Yonai y Ema, tres mujeres ocupadoras en precario, quienes viviendo un profundo malestar ante la no solución del depósito humano en Finca San Juan, deciden en setiembre de 1995, tomar "el relleno", un basurero espacioso para efectuar un asentamiento. La ocupación de un basurero para hacer que su condición de vivienda no continuase siendo un basurero. Este acto lleva a estas tres mujeres entrevistadas a volverse productoras de su historia $y$ a luchar sobre la base de sus sueños: construir su comunidad.

- Es que como es un relleno, echaban de todo, desechos hospitalarios... pedazos de carros, o sea, todo lo que pueda imaginarse que hay en un botadero, basura normal, corriente... lo que hicimos fue, en muchos casos, construir encima de la basura, en otros casos se pudo limpiar esa parte y tirar hacia el fondo del terreno... ahí todos, todos los ranchos están hechos así encima de la basura y de toda (Yonta, entrevista, 2012).

Ya había puesto cuatro cajillas y tirado algunas láminas de zinc y había traído un catre y estaba con mi niña, sin paredes, pero con techo. A las 6 de la mañana está poniendo el recurso, este decía que yo no tenía dónde vivir y que las familias de San Juan no podían darme ninguna respuesta y que yo ocupaba un lugar donde estar con mi hija. Entonces eso nos permitió quedarnos ahí hasta que nos resolviera Sala IV y entonces ahí se generaron las familias que se empezaron a acercar... se empiezan a organizar las familias que van a entrar y como era un basurero, entonces empezamos a limpiar... hicimos construcciones muy pequeñitas, en aquel momento eran de tres metros por tres metros (Yonta, entrevista, 2012).

La diferencia entre los pobladores que ocuparon El Relleno y quienes fueron depositados en Finca San Juan, reside en la posición subjetiva que jugaron al momento de la constitución de su espacio: ser sujetos de acción o ser, al contrario, sus objetos. Concebir una táctica del espacio o recibir la estrategia del espacio impuesta desde el poder. Diferencias para seguir reflexionando en torno a la noción de apropiación. Para los ocupadores del precario El Relleno, el sentimiento de apropiación simbólica y afectiva se dio prácticamente en el momento de la ocupación, el sentimiento de dominar el espacio y luchar por las mejoras; ellas decidieron "construir sobre la basura". Se decidió gradualmente que no eran "las piedras sino los papeles" (formarse llevando cursos y apelando desde el marco de la legalidad), los que iban a dar más fuerza de cambio; este lema es repetido por todas las entrevistadas. De acuerdo a la lectura de Foucault y de Bauman, lo anterior ha dado otro acento a lo que se ha llamado "estética de la existencia"?

$7 \quad$ La existencia, como estilo de vida producto de elecciones, es moderna. La existencia moderna es agitada en la acción inquieta por la conciencia moderna y la conciencia moderna es la sospecha o concienciación del carácter no concluyente del orden existente (Bauman, 1991: 81). 
Respecto a la apropiación espacial, al contar con una historia de luchas colectivas, según las líderes, se ha producido un "sí mismo comunal" que todos reconocen. Se ha ido produciendo una identidad $y$ con esta identidad, una intimidad; es decir, un reconocimiento del otro como parte de sí mismo desde un rasgo constructivo fuera de la abyección.

No obstante, el estigma no ha sido fácil de arrancar frente a las instituciones gubernamentales que podían colaborar:

- Entonces ¿cómo? ¿ustedes de dónde vienen? - De un precario. - ¿Y dónde es el precario? -De Pavas. - No, que pena, pero no recibimos gente de precarios... Todo eso que era tan malo, o sea, uno se devolvía para la casa desmoralizado porque no es que estamos pidiendo que nos regalen, nada más que nos den campo aunque sea ir sacando una a una, las familias... Entonces entramos a preguntar: ¿por qué no le ayudan a los precarios?

- Es que no saben manejar la basura, son unos bulliciosos, son todos... la mayoría son delincuentes (Yonta, entrevista, 2012).

Ellas fueron transformando cada uno de estos "no" en desafíos de cambio, desde la legalidad. Trasmutaron la basura, la bulla, la delincuencia y el licor en retos para luchar por ser un precario modelo en su "comunitas" y en cada uno de estos retos se estableció una condición de plurisaberes: "Si no sabemos, debemos aprender" (Bouillon, 2009). Se iniciaron pidiendo cursos a la municipalidad para aprender sobre el manejo de desechos y esta se vio obligada a responder.

Los plurisaberes se fortalecieron porque iban aprendiendo a manejar grupos, a motivarlos, a comunicarse mejor entre ellos, a hablar públicamente y a redactar solicitudes cuando la situación lo requería. La bulla debía silenciarse por medio de la comunicación y la concientización de que cada uno merecía espacios de no contaminación sónica dentro de su hábitat para estar mejor entre/con los otros.
Se produjeron también los acuerdos para las sanciones, entre aquellos que violentaran las regulaciones, $y$ entre estas regulaciones, el precario El Relleno prohibió la venta de licor. Las mujeres que no trabajaban fuera del espacio doméstico se integraban cada vez más para luchar por sus propios intereses, su vivienda $y$ su vecindario. El esposo de Ema organizó un equipo de fútbol y pudo conseguir donaciones para los uniformes y las bolas. Se trataba de que asistieran un máximo de personas habitantes de El Relleno a todas las reuniones y luchas con las instancias del poder. Lo anterior producía un doble efecto: entusiasmar a los habitantes del precario sobre posibilidades reales de cambio e intimidar a quienes ejercían el poder por la cantidad de personas efectuando las solicitudes.

- Hicimos un Comité de Seguridad Ciudadana... empezamos a pedirle a la Compañía de Fuerza y Luz que nos llevara alumbrado público al precario... no saben manejar la basura, entonces unos roles de limpieza y salíamos dos familias por día de recolección, a recoger todos los sobrantes. [Dijo] la anterior administración que este era el precario más limpio del Área Metropolitana... empezó el precario a transformarse como en una pequeña comunidad donde los aportes de todos son importantes... de hecho es el único precario en el que no se vende droga, no se vende licor... Si somos radicales, si hay alguien vendiendo droga, se asumen las consecuencias, pero se denuncia, $y$ si es necesario $y$-eso desde el inicio del precario-, si hay una venta de droga, si entre todos tenemos que ir a desarmarle el rancho, se lo vamos a desarmar pero no vamos a permitir la venta de droga aquí en el precario... Nos transformamos en autogestionarios en producción del hábitat, porque nos decían bueno, ¿y después de la casa qué?, bueno faltan las escuelas, parques, todo lo que los güilas necesitan para desarrollarse, entonces hagamos una cooperativa auto visionaria en producción real, y no se nos 
muere después de la vivienda... empezamos producir un prefabricado para las casas (Yonta, entrevista, 2012).

La adquisición de un capital de conocimiento (Bordieu, 1993) permitió la conformación de la primera cooperativa en precario en Centro América denominada Coopeberaca, cuyo objetivo es la lucha de un mejor hábitat.

El logro de esta cooperativa fue posibilitar la resistencia constructiva en la batalla contra la desigualdad de la distribución espacial. Es una lucha desde los logros en la inclusión y no meramente desde la destrucción de sus cuerpos o de la destrucción de los otros. Muestra la adquisición y transmisión de un conocimiento aprendido desde el espacio de la vulnerabilidad extrema. Frente a la pasividad inicial del depósito ante la acción del Estado en la década de los 90 , ellos son hoy una pieza clave en la fuerza de los votos distritales, tomando con precaución las promesas de los políticos.

Concluyendo, en Finca San Juan, el estigma tendría tres efectos distintos, pero no exclusivos, en lo que respecta a su relación con la resistencia y la producción de sí:

$\diamond \quad$ Resistencia desde lo abyecto: la identificación con conductas abyectas no es únicamente una respuesta de rabia ante la violencia institucionalizada, sino que posee una función de inclusión en el vínculo social. Ante una gran desorganización identitaria, en ausencia de referentes estables, la organización criminal funge como garante del orden simbólico. Algunos se identifican al estigma $y$ desde esta su apropiación a un ideal del yo marcado por la transgresión de la ley y con la construcción de identificación de goce, cualquier alteridad debe ser destruida anticipándose. Las generaciones impactadas por el trato de depósito y de "basura", fueron respondiendo con una identificación al estigma, volviéndola una identificación positiva y creyendo que la transgresión podía brindar el cambio a su vida "indigna" en un espacio "desapropiado". Lo anterior se evidencia en los vendedores de droga que se arman en grupos "exclusivos" con códigos propios de pertenencia $y$ asignaciones de territorio $y$ puntos de venta bastante precisos.

Este tipo de organización simbólica fortalece los procesos de transgresión, de criminalización y bajo la condición de ser los expulsados, los estigmatizados, se inicia la construcción de "identificaciones de goce" (Lacan, 2001) anticipándose al mundo del Otro que no existe, solo existe el aquí y el ahora porque para ser hay que destruir ya.

$\diamond \quad$ Ninguna resistencia: la otra vía es aquella en la que los efectos de humillación $y$ vergüenza provocan una profecía auto cumplidora: "si se dice que somos así, lo seguiremos siendo". El ser y el estar en el desecho del espacio de la ciudad arriesga a que se incruste el sentimiento de vergüenza. Gaulejac (1996), sociólogo francés interesado en la temática de la vergüenza en la exclusión social, señala con claridad que muchas veces, la suma de injusticias vividas puede gestar sentimientos profundos de vergüenza y con esto, el sentimiento de sentir no merecer una vida mejor. La consecuencia es la pérdida de la fuerza para luchar por el cambio a las propias situaciones de injusticia. Sentir vergüenza de sí, de su comunidad, viene desde una vía directa por la condición de humillación desde el señalamiento, desde la palabra y la mirada de los otros. El resultado final es la aceptación pasiva de una definición identitaria degradante.

$\diamond \quad$ Resistencia desde la búsqueda de inclusión simbólica: algunas personas ante las vivencias de vergüenza y humillación, formulan el deseo de arrancarse este estigma con demostraciones constantes de no ser como los otros dicen que son. En este caso, la elección es no quedarse siempre en la transgresión, ni en la conformidad, sino romper el determinismo y luchar con el arma de los papeles, inscribiendo esta resistencia a través de las vías simbólicas en el Estado de derecho; ejemplo de lo anterior, la formación de Coopeberaca. 
La frase "cambiamos las piedras por los papeles" sintetiza una forma de relación con el colectivo social desde la inclusión por las vías de la legalidad y las luchas comunales; ambas vistas como alternativa a la marginalización producida por la identificación con lo abyecto como transgresión y por la aceptación pasiva de la violencia estatal y económica. Por medio del cuestionamiento sobre el mejor uso de sus cuerpos y el mejor uso del espacio, de sus vidas, El Relleno pasa a transformarse en un lugar de resistencia ante la dominación de quienes deciden la distribución espacial.

\section{BIBLIOGRAFÍA}

\section{LIBROS}

Bauman, Zygmunt. Modernity and ambivalence. Estados Unidos: Cornell University Press, 1991.

Bouillon, Florence. Les mondes du squat. Anthropologie d'un habitat précaire. París, Francia: Presses universitaires de France (PUF), 2009.

Bourdieu, Pierre. Effet de lieu, la misère du monde. París, Francia: Seuil, 1993.

Caillé, Alain. Villes bonnes à vivre/villes invivables: urbanisme, utilitarisme et démocratie. Francia: La Découverte/ mauss, 1999.

Chacón, Laura. Le savoir du psychanalyste. Touluse, Francia: Erès, 2013.

Cordonianu-Thibault, Pierre. Florence Bouillon, le squat : problème social ou lieu d'émancipation? Lectures. París, Francia: Les comptes rendus, 2011. En: <http://lectures.revues.org/5259> [consultado el 19 de diciembre de 2012].

De Certeau, Michel. The practice of everyday life. Estados Unidos: University of California Press, 1984.

Debray, Régis. Eloge de frontières. Francia: Editorial Gallimard, 2010.

Derrida, Jacques. De la grammatologie. Francia: Les Editions de Minuit, 1967.

Foucault, Michel (1976). Historia de la sexualidad. La inquietud de sí. Volumen III. Argentina: Siglo Veintiuno Editores, 2005.

Gaulejac, Vincent. Les sources de la honte. París, Francia: Edition Desclée de Brouwer, 1996.
Goffman, Erving (1961). Asiles. Études sur la condition sociale des malades mentaux. París, Francia: Minuit, 1968.

Lacan, Jacques (1972). Le seminaire XX encore. París, Francia: Éditions du Seuil, 2001.

Wacquant, Loic. Parias urbains: guetto, banlieus, État. Francia: La Découvert, 2006.

\section{REVISTAS}

Veschambre, Vincent. "Traces et mémoires urbaines. Enjeux sociaux de la patrimonialisation et démolition". Cybergeo: European Journal of Geography. París, Francia: Presses universitaires de Rennes (PUR), 2008.

TESIS

Calvo, Catalina; Letendre, Anne y Zuñiga, Sofía. "Análisis de anécdotas de ex integrantes de barras juveniles en Finca San Juan y Metrópilis 1 en Rincón Grande de Pavas. Las barras juveniles como un estilo de vida alternativo". [Tesis de Licenciatura en Trabajo Sociall. Universidad de Costa Rica, 2003.

\section{NOTICIAS}

La Nación. Precarismo pierde fuerza. San José, Costa Rica. 23 de febrero de 1992.

La Nación. En San Juan manda el caos. San José, Costa Rica. 02 de octubre de 1994.

\section{ENTREVISTAS}

Cesar. Habitante de la Finca San Juan, 2012.

Ema. Habitante de la Finca San Juan, 2012.

José Gabriel Román. Líder comunal asignado por el Gobierno. Ministerio de Vivienda y Asentamientos Humanos, San José, Costa Rica, 2012.

Santiago. Habitante de la Finca San Juan, 2012. Yonai. Habitante de la Finca San Juan, 2012. Yonta. Habitante de la Finca San Juan, 2012.

Fecha de ingreso: 07/10/2013 Fecha de aprobación: 16/12/2013 
